\title{
MARXISMO Y CIENCIA FICCIÓN
}

\section{MARXISM AND SCIENCE FICTION}

\author{
Roy Alfaro Vargas \\ Universidad Nacional de Costa Rica
}

Recibido: 13 de marzo, $2015 \bullet$ Aceptado: 29 de junio, 2015

\begin{abstract}
Resumen: Este artículo analiza la relación entre el marxismo y la ciencia ficción, alrededor del concepto de novum y del proceso de extrañamiento cognitivo, que definen la ciencia ficción. Este artículo estudia la teoría y práctica de la ciencia ficción, en la medida que la ciencia ficción es una manifestación de la teoría crítica y, por ende, como parte de una ontología de la congruencia y de la crítica social. Además, se establece una crítica de la ciencia ficción actual que está ligada al neoliberalismo y al proyecto educativo del Banco Mundial.
\end{abstract}

Palabras claves: filosofía social, novum, extrañamiento cognitivo

Abstract: This article analyzes the relation between Marxism and science fiction around the concept of novum and the process of cognitive estrangement, which define science fiction. This article studies the theory and practice of science fiction, so long as science fiction is a manifestation of the critical theory and, therefore, as a part of an ontology of congruence and of the social critique. Also, it is established a critique of the current science fiction what is linked to Neoliberalism and to the pedagogical project of World Bank.

Keywords: Social Philosophy, Novum, Cognitive Estrangement

\section{Introducción}

Porque la filosofía es práctica y se alimenta de lo cotidiano, sumida en un proceso histórico, no puede ser indiferente a las condiciones sociales donde pretende existir y que son su propia condición de posibilidad, en tanto superación (Aufhebung) de su en sí, al devenir parte del para sí social, del proyecto social, de la Política (con mayúscula). 
La filosofía no puede despreciar lo que parece trivial en lo cotidiano; esta debe comprometerse con la discusión sobre los procesos de ingeniería social, que conllevan asumir el fenómeno (la inmediatez) y sumirlo en la totalidad histórica, lógico-discursiva, en su necesidad y su contingencia: la práctica filosófica nos permite retornar de los procesos metonímicos, sinecdóquicos de la (post)postmodernidad, al todo que se diluye en las parcialidades cantorianas, en la inacción del conjunto vacío $(\varnothing)$ que guía no solo la reflexión cultural y política actual, sino también la lógica económica de nuestros tiempos.

La crisis sistémica que se manifestó con el estallido de la burbuja financiera en el 2008 desgarró visceralmente al neoliberalismo, pero también a su ideología, el postmodernismo. China y Rusia aparecieron entonces socavando el status quo de la hegemonía estadounidense, al igual que el marxismo retomó poco a poco un lugar preponderante en la escena político-intelectual. Žižek (2014a y 2014b) se declara marxista y los nuevos estudios culturales se ligan al marxismo (véase Fuchs, 2014), al tiempo que la derecha académica habla de post-postmodernismo, ${ }^{1}$ como un medio para aferrarse a las políticas neoliberales. En otras palabras, existe hoy un clima de fuerte oposición entre las fuerzas políticas que asumen el contexto actual como una lucha de clases (el marxismo) y aquellas fuerzas que siguen ancladas en el relativismo cultural y el nihilismo onto-gnoseológico —el neoliberalismo (post)postmoderno- - Y es en este marco que se comienza a mercadear un producto cultural (literario, en este caso) con la etiqueta de ciencia ficción (CF) en Costa Rica; fenómeno que ha tenido especial auge desde el 2008, donde han colaborado diversas editoriales, como: la Editorial de la Universidad Estatal a Distancia, Uruk Editores, el Grupo Nación, Clubdelibros e Iván Molina Jiménez (como sello editorial).

No obstante, el año 2014 marcó dentro de un (hasta ese momento) incontestable contexto con tintes neoliberales dentro de la denominada CF en Costa Rica la aparición de la crítica marxista en el ámbito de tal fenómeno literario. Así, en el 2014, se publicaron dos textos: «La ficción de Iván Molina Jiménez» (Alfaro, 20132) y «El novum en la ciencia ficción costarricense» (Alfaro, 2014b), el primero en la revista Letras de la Universidad Nacional

1 Véase Alfaro (2014a).

2 Este texto realmente, a pesar de estar fechado 2013, salió en el 2014. 
y el segundo en la Revista de Filología y Lingüística de la Universidad de Costa Rica, que no solo demuestran que en Costa Rica no hay hasta hoy una verdadera producción de $\mathrm{CF}$, sino que también se muestra la conexión que existe entre el proyecto pedagógico-ideológico del neoliberalismo local y global y la mal denominada CF costarricense.

Esto nos lleva ineludiblemente a reflexionar sobre el rol histórico del marxismo en el estudio de la CF, así como sobre los aportes que hoy este paradigma puede aportar.

\section{Marxismo, Darko Suvin y la CF}

Suvin es el más importante teórico de la CF, la cual

es definida por Suvin en términos de un novum textual (una innovación ontológica) que es racionalizada por el discurso de la ciencia. El novum no tiene que ser científico (es decir, posible en términos de nuestro actual conocimiento) sino que este tiene que ser representado como congruente con la epistemología científica (Gomel, 2014, p. 303).

Así, la noción de una innovación ontológica es primordial dentro del desarrollo de la CF, en tanto que implica «la conjunción de la teoría crítica y la CF [lo cual] no es fortuito sino fundamental» (Freedman, 1987, p. 182). Asimismo, la innovación ontológica introduce la asunción de la negatividad, en cuanto la CF se fundamenta en la crítica de lo real, a través de la construcción de un posible futuro, lo cual se define como la superación dialéctica (Aufhebung) del contexto empírico del autor de CF.

En otras palabras, la CF rompe con la realidad empírica donde se sitúa el autor de CF. Así, para la CF, «el centro de interés es la creación de una nueva realidad» (Zgorzelski, 1979, p. 299). La CF crea mundos que «necesariamente se desvían del mundo real y los modos en los cuales estos se desvían son el núcleo y el sentido de la creación de CF» (Lem, 1973, p. 31). Este desvío (la Aufhebung del mundo empírico del autor de CF) conlleva, dentro del ámbito científico de la CF, un dominio del desarrollo científico-tecnológico actual, como punto discontinuo desde donde se parte, el cual, a su vez, se

3 Las traducciones de textos aparecidos en la bibliografía en inglés, francés, portugués y alemán son mías. 
inserta en la continuidad de la historia de la ciencia, lo cual permite acceder al planteamiento de posibles desarrollos tecnológicos, como manifestación de «lo Mismo por lo Otro» (Renault, 1980, p. 115). En otras palabras, la CF funciona mediante un mecanismo (el cual abordaremos adelante) donde se da «la negación abstracta de una realidad positiva» (Renault, 1980, p. 118).

Así, la CF y la dialéctica comparten una visión ontológica no anclada en la positividad, en lo dado, sino que se plantea junto al Ser (no substancializado) un Deber Ser, es decir, el Ser en cuanto devenir. La CF parte de una concepción de la realidad no vista como igualdad, como tautología $(A=A)$, sino como congruencia $\left(A \equiv A^{4}\right)$, en tanto que la relación Ser-Deber Ser implica el asumir unidas dialécticamente, la identidad y la diferencia, con lo cual se rompe el esquema positivista de una identidad petrificada y de la diferencia fenomenológica (la différance derridiana, por ejemplo) que se inserta en un particularismo que pierde su fundamento al aparecer como discontinuidad absoluta, y también pierde su existencia al desligarlo de lo material (el problema de la arreferencialidad postmoderna) y reducirlo a puro discurso. En términos expresados por Suvin, se puede afirmar que la CF se asienta en «una epistemología relacional y situacional y no en una ontología doctrinariamente aceptada» (2000, p. 258).

Asimismo, esta ontología de la congruencia $(\mathrm{A} \equiv \mathrm{A})$ dentro de la $\mathrm{CF}$ contiene algunas particularidades. De hecho, en tanto la CF se construye sobre la base del conocimiento científico-tecnológico, tiene una base material e histórica, ya que esta requiere en su elaboración no solo el manejo conceptual de lo científico-tecnológico, sino también del proceso histórico que hay tras la existente tecnología, como un medio para plantear una tecnología y una ontología posibles.

Por otra parte, el amarre funcional y referencial de la CF y lo científico-tecnológico requieren necesariamente una articulación entre lenguaje y realidad, en cuanto «todo lenguaje es referencial» (Gaskin, 2013, p. 2905) y en tanto se rechaza «la idea de que el mundo es textual en cualquier sentido literal» (p. 240). En este marco, la CF tiene dos anclajes con la materialidad del mundo: a) su ligamen con el conocimiento científico-tecnológico

4 Para ampliar sobre esta idea véase Kojève (2013).

5 Idea también planteada por Alfaro (2005). 
y b) en tanto «el lenguaje poético es un modo de aprehender la realidad» (Gaskin, 2013, p. 290).

Con todo esto, tenemos una CF cuya ontología se define por la congruencia, la cual permite insertar la diferencia dentro de lo dado, en un proceso donde el lenguaje se asume en toda su referencialidad, a través de la relación dialéctica entre la forma (el texto de CF) y el contenido (la referencialidad crítica y material de la Aufhebung).

Mediante esta ontología, la CF se define como «una literatura mutante, revolucionaria» (Eizykman, 1975, p. 164) que «transforma el orden en caos; como la fuerza del devenir» (Eizykman, 1983, p. 24), permitiéndole a la CF «la capacidad de concebir y promover perspectivas de una permanente conmoción de la Historia» (Eizykman, 1985, p. 78).

En el marco de esta reflexión sobre la ontología de la congruencia y la CF, es claro que concebir la CF en términos de una ontología positivista o de una fenomenológica es, si no problemático, inviable. ¿Por qué? Porque dentro de una ontología positivista la CF se vería atada a una substancialización de lo dado, del status quo (en términos onto-gnoseológicos y políticos, por su reticencia a la transformación de la sociedad burguesa), y a un rígido realismo estético, en cuanto la negatividad de la que hablaba arriba no es, en el marco positivista, coherente con los principios empiristas de la ciencia positivista. En el ámbito de las ciencias positivistas, el par realidad-posibilidad se escinde, perdiendo la posibilidad de su carácter negativo (como salto cualitativo) y se absorbe en una noción de realidad que lo pone en función de principios cuantificables, donde la negatividad dialéctica es cerrada en un espectro de probabilidades estadísticas de lo dado, del objeto. Aquí, la CF pierde su carácter crítico y se sume en el punto de repetitividad, entendido como «una apropiación de lo cotidiano que lo presupone inalterable» (Alfaro, 2007, p. 10), con lo que la CF (asumido el término de CF en una perspectiva mercadotécnica) devendría una CF distópica, que sería «explícita o implícitamente una defensa del status quo» (Fitting, 2010, p. 141).

Dentro de la ontología fenomenológica, por otra parte, que en sus versiones postmodernas se liga al giro lingüístico (con la noción de arreferencialidad y su relativismo epistemológico, así como con sus características fundamentales) y su consecuente rechazo de la ciencia, del conocimiento, del sujeto y de la materialidad, claramente se desemboca en una incapacidad, 
por parte de esta ontología (disgregada, deconstruida, reducida a lenguaje) de dar cabida a un género, como la CF, basado en la ciencia y la tecnología. Volviendo a la ontología de la congruencia, Suvin planteó entonces el novum y el extrañamiento cognitivo como herederos de esta ontología.

\section{El novum y el extrañamiento cognitivo}

Spiegel afirmó correctamente que «lo que caracteriza la ciencia ficción y la diferencia de la fantasía es el novum» (2013, p. 2476). O sea, el novum permite definir la CF como «un género literario [cinematográfico, etc.] cuyas condiciones necesarias y suficientes son la presencia e interacción de extrañamiento (estrangement) y cognición, y cuyo recurso formal fundamental es una estructura imaginativa alternativa al ambiente empírico del autor» (Suvin, 1979, pp. 7-8).

Suvin señaló que: «El novum es una categoría de mediación cuya potencia explicativa deriva de su rara función de puente entre los dominios literarios y extra-literarios, ficticios y empíricos, formales e ideológicos, en pocas palabras de su inalienable historicidad» $(1979$, p. 64). Dicho en otras palabras, «la CF parte de una hipótesis de ficción (orden "literario") y la desarrolla con rigor por extrapolación (orden "científico")» (Suvin, 1973, p. 100), en donde hay «una epistemología relacional y situacional y no una ontología aceptada» (Suvin, 2000, p. 258). Para la CF, entonces, «la extraña novedad es su raison d'être» (Suvin, 1972, p. 381).

De esta manera, la CF conlleva un proceso de extrañamiento (Verfremdung) y cognición, que se ampara en lo que Suvin llamó un recurso formal, es decir, una estructura de la imaginación que no se corresponde con el contexto empírico del autor. En otras palabras, el Ser se define como el contexto empírico del autor (lo concreto) y el producto denominado CF se fundamenta entonces en el Deber Ser, o sea, en el contexto diegético (narrativo, discursivo, lógico) de la CF (lo abstracto), que en tanto forma refiere al contexto empírico del autor, pero desplazándolo y condensándolo en la diégesis textual. Así, la CF presenta una cuestión social perteneciente al contexto empírico del autor, pero en una construcción diegética (el relato literario o la trama cinematográfica, por ejemplo) plagada de una tecnología

6 La noción de novum «es en la investigación de la ciencia ficción en general aceptada» (Spiegel, 2013, p. 247). 
no existente en el contexto empírico del autor y cuya representación posee un grado suficiente de plausibilidad científico-tecnológica. Más claramente dicho, la representación en la CF ejecuta fenoménicamente un mundo diegético marcado por un desarrollo científico-tecnológico totalmente alejado del momento en que se produce tal CF y que aparece como algo extraño al receptor. Sin embargo, en lo esencial, en lo referente a la problemática y crítica sociales, el texto de CF ofrece información, conocimiento, sobre los problemas sociales que aquejan el contexto empírico del autor como tal. Así, el novum, a través del efecto de extrañamiento y del proceso cognitivo que implica, «es —y debe ser- el suministro de un reflejo amedrentador y distanciador de la realidad demasiado familiar; el propósito del reflejar es provocar tanto asombro como preocupación» (Bloch, 1970, p. 125).

Esto permite, desde luego, separar emocionalmente al receptor de CF de su propia problemática (extrañamiento) para que la pueda aprehender «en frío», sin vínculos emocionales y sí racionalmente; a la vez que no solo le brinda información de lo que sucede en su contexto, sino que además se le puede ofrecer una alternativa: «El novum es producto de procesos materiales; este produce efectos que pueden ser lógicamente derivados de las causas del novum, en el mundo social y material; y este es plausible en términos de la lógica histórica» (Csicsery-Ronay, 2003, p. 119). En este sentido, la CF y el marxismo comparten el hecho de buscar objetivos «más allá del texto literario [cinematográfico, etc.] específico» (Burling, 2009, p. 236).

El novum se aleja del objetivismo positivista que tiende a caer en un simple estructuralismo, en relación con los productos culturales como la $\mathrm{CF}$, al ver en estos solo una suma de recursos formales, sin tomar en cuenta al sujeto (como particular y como sociedad, o sea, como contenido) en el desarrollo mismo del objeto. Asimismo, el novum no da espacio al subjetivismo de la fenomenología, al referir por un lado (a través de la cognición) a un proceso material, real y objetivo, y, por otro lado, al basarse en el conocimiento científico-tecnológico. El novum y la CF suponen una relación dialéctica entre sujeto y objeto.

Como señaló Spiegel, en relación con el novum, «Suvin no separa claramente en su definición de CF entre los aspectos ficticios, estilístico-formales y receptivos» $(2006$, p. 20). Dentro de una teoría crítica, los elementos estilístico-formales a veces se ven como forma y a veces como contenido, al 
igual que los receptivos refieren a veces al dispositivo estructural del texto de CF y a veces a la cuestión política que yace en el contexto empírico del autor/receptor: a veces priva lo intradiegético (en literatura o cine) y a veces lo extra-diegético (como praxis material).

Claramente, la cuestión dialéctica referente al novum en la CF gira alrededor de las categorías de espacio y tiempo, las cuales permiten en un juego de espacios (el contexto empírico del autor y el contexto diegético de la $\mathrm{CF}$ ) introducir el principio de entropía dentro del proceso del extrañamiento cognitivo.

\section{Tiempo, espacio y CF}

Diegéticamente,

En la literatura [el cine, etc.] de CF, el lector [receptor] obviamente permanece en sitio, en cuanto él es el presente de la lectura que constituye el punto de partida de este aparato temporal; pero el agregado relato/narración da un salto hacia delante ya que, como el relato se supone se está desarrollando en el futuro, la narración que lo «reconstituye» en el tiempo pasado debe necesariamente estar ocurriendo en el futuro del futuro (Eizykman, 1985, p. 677).

De este modo, el presente de la lectura se experimenta a través de una narración en tiempo pasado, por parte de un narrador que se coloca en el futuro de los hechos narrados, utilizando una forma verbal en pasado. Si a esto le sumamos el hecho de que la CF establece la superación (Aufhebung) que rompe, en cuanto su ligamen con la teoría crítica y la ontología de la congruencia, el principio de identidad $(\mathrm{A}=\mathrm{A})$ del realismo estético (marcado por un no extrañamiento cognitivo, ya que presenta tentativamente las cosas tal y como son, con el fin de aprehender cognitivamente lo dado, lo existente, sin «alteraciones») y asume el sistema social como lo que es, es decir, como un sistema abierto que tiene su propio proceso entrópico (la tendencia al desgaste); entonces la CF no se ampara en una relación tiempo y espacio, al estilo de la física newtoniana, sino que se asienta en una visión

7 A favor de esto, se puede agregar: «La estructura temporal común a toda una parte de la CF, situada en nuestro futuro y en el pasado del narrador, constituye una característica específica de esta literatura» (Favier, 1972, p. 70). 
einsteiniana, donde el espacio-tiempo es una sola cosa y no existe separación entre ambos, como sucede en Newton.

Así, el principio de entropía y el espacio-tiempo einsteiniano permiten, en oposición a las fuerzas reaccionarias que alucinan con un sistema social cerrado (sin cambios, como pasa con el capitalismo en la visión neoliberal), una CF que introduce la contingencia dentro de la necesidad (es así y no de otro modo) de la positividad del sistema existente, donde esta contingencia «es a menudo concebida, explícitamente, como un medio de resistencia o lucha contra una tiranía o poder demasiado opresivos» (Eizykman, 1983, p. 30).

La CF, entonces, implica una estructura tempoespacial, en la cual existe una: relación indisoluble entre tiempo y espacio, en donde la conciencia es el producto de la interiorización de esa relación, a través del principio entrópico (segunda ley de la termodinámica). Luego, el tiempo y el espacio adquieren una base sólida y material, con valores objetivos (la lógica del universo) y con valores subjetivos (la lógica socio-individual) (Alfaro, 2011a, p. 148).

Sin olvidar que también es fundamental en este proceso la absoluta referencialidad del lenguaje.

Dentro de este marco, la CF, en su relación con la estructura tempoespacial (como un modelo tempo-espacial) permite salirse «del proceso de interpretación-producción (...) para crear las condiciones cognitivas que colaboren en la transformación social» (Alfaro, 2011b, p. 19), en tanto, por la misma estructura narrativo-temporal de la diégesis de la CF, «hay una relación pasado-presente-futuro, que es aprehensible mediante la dialéctica negativa» (Alfaro, 2008, p. 174).

La CF es un género total, en cuanto permite aprehender-plantear la praxis humana como desenvolvimiento del tiempo-espacio mismo. La CF implica una antropología filosófica que rescata al ser humano como sujeto de cambio.

Es claro que la CF tiene características propias definidas con precisión megatextual ${ }^{8}$ e históricamente, que hacen ver la falsedad de la afirmación de Haywood, quien afirmó que: «La ciencia ficción es un género con lími-

8 El megatexto es «el extenso y mutable cuerpo de referencias que la mayoría de los artistas de CF y audiencias consideran ser el tesauros subcultural compartido por el género» (Csicsery-Ronay, 2009, p. 362). 
tes notoriamente nebulosos» $(2011$, p. 8) y que también evitan caer en el reduccionismo conservador de Luokkala, quien vio en la CF simplemente «un vehículo para explorar la ciencia actual y como un trampolín para discutir algunos de los excitantes tópicos que están hoy siendo investigados» (2014, p. 1). Ambas posiciones ejemplifican la línea neoliberal de la CF, que quiere una CF hibridizada con la fantasía — contradiciendo el hecho de que «lo que caracteriza la ciencia ficción y la diferencia de la fantasía es el novum» (Spiegel, 2013, p. 247) y donde se asume como esencial el novum y el extrañamiento cognitivo en la CF, para distinguirla de la fantasía-. Es decir, sin novum y sin crítica social, se busca una CF donde el tiempo y el espacio estén separados, en una perspectiva enteramente newtoniana, que hace del tiempo algo no necesariamente entrópico; luego, no habría un sistema capitalista en desintegración, sino eterno, siempre igual a sí mismo.

La posición de Haywood y Luokkala se observa en mercancías que saturan el mercado cinematográfico, con la etiqueta de $\mathrm{CF}$, pero que privilegian el elemento fantástico: lo paranormal, lo místico, etc.; en películas, por ejemplo, como: Under the Skin (2013), Lucy (2014), I Origins (2014), Interstellar (2014), Trascendence (2014), Debug (2014), Zodiac: Signs of the Apocalyse (2014), etc.

Sin embargo, la CF en esta versión neoliberal conlleva un proceso de formalización de este género literario y fílmico, en cuanto proceso de socialización ligado a grupos formales (por ejemplo, cursos universitarios sobre $\mathrm{CF}$, programas educativos que involucran el estudio de la $\mathrm{CF}$, etc.), con lo cual no solo se legitimaría la nulificación de la noción de novum, sino que a la vez se insertarían en los procesos de socialización valores y patrones cognitivos propios de la ingeniería social neoliberal.

En este marco, Gomes-Malauf y de Souza señalaron:

La producción literaria [y de otros tipos] envolviendo el género de ciencia ficción se transformó en una fuente de información en tiempo real e imaginario. En tiempo real, es presentado al público lo que en la Ciencia se discute actualmente y aquellos direccionamientos presentados por las nuevas investigaciones; en tiempo imaginario, la ciencia ficción transforma el caminar de las investigaciones científicas en un «futuro posible», ofreciendo la posibilidad de hacerse Ciencia, antecediendo los resultados por ser alcanzados. Al trabajar entre estos dos mundos, la ciencia ficción favorece el acceso a 
diferentes producciones de la Ciencia, o dando oportunidad, con base en una obra artística, al contacto con las transformaciones que el hombre de Ciencia viene imprimiendo al mundo (2008, p. 280).

En otras palabras, la CF neoliberal asume, sin novum alguno, «las posibilidades que la CF da en la exploración de múltiples aspectos de valor didáctico en las aulas de ciencia» (Piassi y Pietrocola, 2009, p. 538). En este sentido, lo importante es «la utilización de la CF y su contribución a la motivación del alumnado» (Petit y Solbes, 2012, p. 71), en cuanto

en el camino de la ciencia a la ciencia ficción pasando por la divulgación científica, es posible que la respetabilidad social y la verosimilitud temática desciendan, mientras que, por el contrario, suben la facilidad de comprensión y el alcance de su difusión (Barceló-García, 2005, p. 7).

Hay que recordar, en este contexto de la CF, que las reformas en las políticas educativas tienen nombre y apellido: el Banco Mundial. Hoy, «el Banco Mundial es el mayor participante en los discursos globales acerca de la educación» (Spring, 2009, p. 29). Las reformas en las políticas educativas vienen de las ideologías del Banco Mundial y reflejan una ideología neoliberal (Zajda, 2010), donde se enfatizan los valores del mercado y la competencia individual (Spring, 2009). De esta manera, «las naciones alrededor del mundo comenzaron a organizar los sistemas nacionales de educación para suplir trabajadores para las fábricas y promover el aprendizaje científico y matemático, para el desarrollo industrial y militar» (Spring, 2006, p. 2; cursiva mía). La agenda política que se oculta tras todo esto «es establecer y mantener una visión conservadora y acrítica de la enseñanza y el aprendizaje» (Smyth, 2011, p. 27). Es una visión que responde al Estado neoliberal, a la globalización y a la economía del conocimiento, que centra la enseñanza y el aprendizaje en función del mercado. Asimismo, como lo indicaron Brown y Lauder, existe de fondo en la pedagogía del Banco Mundial un proceso de rutinización, tanto en oficinas como en fábricas, cuyos trabajos «pueden requerir algún grado de educación pero no la clase de creatividad e independencia de juicio que es a menudo asociado con la retórica de la economía del conocimiento [y de la actual pedagogía, por ende]»(2010, p. 234; cursivas mías). 
Con esta visión de fondo, «la ciencia ficción ha logrado ya, por sus propios méritos, llegar a formar parte de los currículos de las high schools y universidades anglosajonas y, poco a poco, se incorpora también en el mundo docente en habla hispana» (Barceló-García, 2005, p. 4).

El problema con este proceso de formalización/socialización elaborado alrededor de la neoliberal CF es que la producción/escritura de CF queda sometida a dos fuerzas opuestas que se excluyen mutuamente, lo cual repercute directamente sobre la calidad de la CF. Por un lado, la concepción neoliberal de CF requiere de una CF que aborde la elaboración de una diégesis de un contenido científico-tecnológico, que sirva de punto de partida para la incentivación de un pensamiento científico (entendido en términos tecnocráticos, en tanto se pretende eliminar, dentro de la CF, el novum y el proceso de crítica social de tal desarrollo cognitivo). No obstante, por otro lado, esta incentivación científica, que debe fundamentarse en todo un desarrollo lógico y crítico, se ve frenada por la necesidad de control social dentro de las sociedades capitalistas, que cada vez más se mueven hacia la limitación de las libertades civiles (el derecho a la protesta, por ejemplo) y que, en el caso de la CF, se dirigen a redefinirla como fantasía, es decir, como el reino de lo imposible; al contrario de la CF tradicional que enfatiza lo posible a partir de lo real-racional.

\section{In Time: un ejemplo de CF à la marxista}

La noción de CF lleva consigo hacer ficción de la ciencia, o sea, sin perder la reelaboración artística (literaria, cinematográfica, etc.), el elemento científico-tecnológico es crucial en este género, que presenta de hecho la tecnología futurista (anclada en la plausibilidad científica del hoy, del contexto empírico del autor de $\mathrm{CF}$ ) como elemento diegético que materializa el cambio en la sociedad, en función de la criticidad del novum, como un producto ontológico-congruente.

En este sentido, la película In Time (2011) caracteriza adecuadamente tal concepción de CF. Esta película representa una sociedad en el futuro, en la cual el dinero, como lo conocemos hoy, ha dejado de existir. Asimismo, el desarrollo computacional ha permitido la implementación de dispositivos (algún tipo de «chips» biológicos) que están insertados en el cuerpo de las personas. 
Estos chips permiten convertir (y aquí yace la reelaboración artística en tanto metáfora cinematográfica) el tiempo de vida en moneda. Es decir, al comprar algo se paga con tiempo de vida, el cual es descargado del chip del comprador. El tiempo de vida es la moneda de uso diario y es lo que permite la reproducción-circulación del capital, así como la consecuente efectivización de la plusvalía.

Es claro que el chip, como portador del tiempo de vida, remite a la apropiación del trabajo no pago (que finalmente es el tiempo de vida del obrero que gasta produciendo sin pago alguno) que realiza el trabajador y que es apropiado por el capitalista.

En el caso de In Time, este tiempo de vida, que no es más que valor acumulado, se guarda en bancos, se roba como el dinero y se devalúa por la inflación. De igual modo, esta película pone un énfasis fundamental en la crítica del capital financiero (muy apropiado para nuestros tiempos), el cual se vuelve el foco del ataque revolucionario, por parte de los protagonistas.

El proceso crítico, revolucionario, inicia con la muerte de la madre del protagonista (Will Salas, interpretado por Justin Timberlake), a quien su cronómetro biodigital le llega a marcar cero. Esto sucede porque el sistema, que favorece a la burguesía financiera, manipula el costo de vida (haciendo subir constante e inesperadamente los precios de bienes y servicios) para obligar a la clase baja a trabajar más y, por consiguiente, a generar más plusvalía y beneficio económico para la clase alta. Así, con la muerte de la madre del protagonista y el obsequio que le hacen a este de un poco más de un siglo de tiempo, inicia un proceso que socava los fundamentos económicos y éticos del capitalismo, en una versión darwinista.

Hasta aquí, In Time representa la situación experimentada (extra-diegética y literariamente) por nosotros a nivel global desde hace ya décadas, así como los problemas altamente exacerbados que se generaron con la explosión de la burbuja financiera en el 2008. La presentación de este escenario en un espacio-tiempo futuro nos permite visualizar el hoy sin cargas emotivas (como la ansiedad de cada uno por sobrevivir) y nos enfrenta más racionalmente con nuestra propia situación, o sea, se da un extrañamiento cognitivo dentro de parámetros que le permiten al espectador desarrollar empatía por la causa de los protagonistas. 
Volviendo a la trama de esta película, el protagonista es obsequiado por un hombre acaudalado, que antes de suicidarse le regala el siglo de tiempo que mencioné arriba, lo cual termina llamando la atención de la policía (los cronometradores), lo cual conlleva la persecución por parte de los aparatos represivos del Estado. En este marco, él con todo ese tiempo de vida viaja a Nueva Gereshk, donde vive la burguesía, y conoce a la hija de un banquero (llamada Sylvia Weis, interpretada por Amanda Seyfried), la cual se une a él en una cruzada que recuerda, al estilo de Robin Hood, el «robar» lo que los ricos han robado para entregárselo a los pobres y destruir así el sistema financiero que sostiene el capitalismo, en la película señalada.

In Time plantea un final abierto (donde la acumulación de riqueza se cuestiona sin tapujos, en nombre de la sobrevivencia del día a día y sin explotar al prójimo), el cual invita al espectador no solo a la reflexión, sino también a la acción política, al estilo de los protagonistas que usan el sistema (su carácter digital, virtual) contra el sistema mismo, para distribuir la riqueza entre la clase baja. La salida del capital financiero a la economía real, dentro de la trama, termina socavándolo, a la vez que inicia un proceso socialista para reestructurar la sociedad.

La implementación de una tecnología futurista plausible (dada como metáfora) y la crítica social definen el novum en In Time, así como en películas como Elysium (2013) o la clásica película alemana Metropolis (1927).

\section{Conclusión}

La CF asume «las intersecciones de la tecnología, la teoría científica y la práctica social» (Csicsery-Ronay, 2003, p. 4) en un proceso al cual es inherente un novum que «funda un efecto estético con una relevancia ética e histórica» (Csicsery-Ronay, 2011, p. 51) y que diferencia a la CF de los géneros fantásticos, que se basan en lo paranormal, en lo no posible científicamente, etc.

En esta perspectiva, el marxismo ofrece a la CF un marco ontológico-congruente, basado en una crítica de lo dado y fundamentado en lo material, dentro de una noción de espacio-tiempo que provee cognitivamente la posibilidad de establecer modelos mentales tempo-espaciales, así como todo un espectro de categorías (el fenómeno y la esencia, la forma y 
el contenido, la realidad y la posibilidad, lo necesario y lo contingente, etc.) dentro de la unidad dialéctica de Ser y pensamiento (lo cual restablece la referencialidad del lenguaje).

Sin duda, la historia de la CF está determinada por el marxismo: «La teoría marxista ha jugado un importante rol en la crítica de CF (...) Desde los años 1960, muchos de los más sofisticados estudios de CF han sido o explícitamente marxistas en su orientación o influenciados por conceptos marxistas» (Csicsery-Ronay, 2003, p. 113).

\section{Referencias}

Alfaro, R. (2005). Sociología dialéctica de la literatura: cuestión de método. Revista de Ciencias Sociales, III-IV(109-110), 151-156.

Alfaro, R. (2007). Antropologías literarias: prolegómenos a la praxis textual. Praxis 59, 7-17. Alfaro, R. (2008). El rol de los modelos mentales espaciales en la aprehensión literaria. Revista de Ciencias Sociales, III(121), 167-178.

Alfaro, R. (2011a). Tiempo y espacio como ideología. Praxis 66, 145-154.

Alfaro, R. (2011b). Modelos mentales tempo-espaciales. Revista de Ciencias Sociales, IIIIV(133-134), 13-22.

Alfaro, R. (2013). La ficción de Iván Molina Jiménez. Letras 53, 201-217.

Alfaro, R. (2014a). Post-postmodernismo. Reflexiones 93 (2), 103-113.

Alfaro, R. (2014b). El novum en la ciencia ficción costarricense. Revista de Filología y Lingüística, 40(1), 129-140.

Barceló-García, M. (2005). Ciencia y ciencia ficción. Revista Digital Universitaria, 6(7), 1-10.

Besson, L. (Director). (2014). Lucy. Universal Pictures y Canal+.

Bloch, E. (1970). Entfremdung, Verfremdung: Alienation, Estrangement. The Drama Review: TDR, 15(1), 120-125.

Blomkamp, N. (Director). (2013). Elysium. TriStar Pictures, Sony Pictures Entertainment (SPE), Media Rights Capital, QED International, Simon Kinberg Productions.

Brown, P. \& Hugh, L. (2010). Economic globalisation, skill formation and the consequences for higher education. In Michael W. Apple, Stephen J. Ball and Luis Armando Gandin (eds.). The Routledge International Handbook of the Sociology of Education. Pp. 229-240. Londres and Nueva York: Routledge.

Burling, W. J. (2009). Marxism. In Mark Bould, Andrew M. Butler, Adam Roberts and Sherryl Vint (eds.). The Routledge Companion to Science Fiction. Pp. 236-245. London and New York: Routledge.

Cahill, M. (Director). (2014). I Origins. Verisimilitude/WeWork Studio/Bersin Pictures.

Csicsery-Ronay, I. Jr. (2003). Marxist theory and science fiction. In Edward James and Farah Mendlesohn (eds.). The Cambridge Companion to Science Fiction. Pp. 113-124. Nueva York: Cambridge University Press. 
Csicsery-Ronay, I. Jr. (2009). Empire. In: Mark Bould, Andrew M. Butler, Adam Roberts y Sherryl Vint (eds.). The Routledge Companion to Science Fiction. Pp. 362-372. Londres y Nueva York: Routledge.

Csicsery-Ronay, I. Jr. (2011). The Seven Beauties of Science Fiction. Middletown, Connecticut: Wesleyan University Press.

Eizykman, B. (1975). On Science Fiction. Science Fiction Studies, 2(2), 164-166.

Eizykman, B. (1983). Chance and Science Fiction: SF as Stochastic Fiction. Science Fiction Studies, 10(1), 24-34.

Eizykman, B. (1985). Temporality in Science-Fiction Narrative. Science Fiction Studies, 12(1), 66-87.

Favier, J. (1972). Les jeux de la temporalité en science-fiction. Littérature. 8, 53-71.

Fitting, P. (2010). Utopia, Dystopia and Science Fiction. In Gregory Claeys (ed.). The Cambridge Companion to Utopian Literature. Pp. 135-153. Nueva York: Cambridge University Press.

Freedman, C. (1987). Science Fiction and Critical Theory. Science Fiction Studies, 14(2), $180-200$.

Fuchs, C. (2014). Karl Marx y el estudio de los medios y la cultura hoy. Telos. Revista de Estudios Interdisciplinarios en Ciencias Sociales, 16(3), 495-535.

Gaskin, R. (2013). Language, Truth, and Literature. A Defense of Literary Humanism. Oxford: Oxford University Press.

Glazer, J. (Director) (2013). Under the Skin. Film4.

Gomel, E. (2014). Narrative Space and Time. Representing Impossible Topologies in Literature. Nueva York and Londres: Routledge.

Gomes-Maluf, M. y Robinson de Souza, A. (2008). A ficção científica e o ensino de ciências: o imaginário como formador do real e do racional. Ciência E⿱ Educação, 14(2), 271-282.

Haywood, R. (2011). The Emergence of Latin American Science Fiction. Middletown, CT: Wesleyan University Press.

Hewlett, D. (Director) (2014). Debug. Copperheart Entertainment.

Hogan, W. D. (Director) (2014). Zodiac: Signs of the Apocalypse. SyFy Original Movies/ Cinetel Films/Reel One Pictures.

Kojève, A. (2013). ¿Qué es la dialéctica? Revista de Ciencias Sociales. I(139) 91-102.

Lang, F. (Director) (1927). Metropolis. U.F.A.

Lem, S. (1973). On the Structural Analysis of Science Fiction. Science Fiction Studies, 1(1), 26-33.

Luokkala, B. B. (2014). Exploring Science Through Science Fiction. New York, Heidelberg, Dordrecht, London: Springer.

Niccol, A. (Director) (2011). In Time. Regency Enterprises, New Regency Pictures, Strike Entertainment.

Nolan, C. (Director) (2014). Interstellar. Warner Bros. Pictures/Syncopy/Paramount Pictures/Legendary Pictures/Lynda Obst Productions.

Petit, M. F. y Solbes, J. (2012). La ciencia ficción y la enseñanza de las ciencias. Enseñanza de las Ciencias. Revista de Investigación y Experiencias Didácticas, 30(2), 69-86.

Pfister, W. (Director). (2014). Trascendence. Warner Bros. Pictures/Alcon Entertainment. 
Piassi, L. y Pietrocola, M. (2009). Ficção científica e ensino de ciências: para além do método de 'encontrar erros em filmes'. Educação e Pesquisa, 35(3), 525-540.

Renault, G. (1980). Science Fiction and Cognitive Estrangement: Darko Suvin and the Marxist Critique of Mass Culture. Discourse 2, 113-141.

Smyth, J. (2011). Critical Pedagogy for Social Justice. New York: Continuum.

Spiegel, S. (2006). Der Begriff der Verfremdung in der Science-Fiction-Theorie. Ein Klärungsversuch. Quarber Merkur. Franz Rottensteiners Literaturzeitschrift für Science Fiction und Phantastik 103/104, 13-40.

Spiegel, S. (2013). Science Fiction. In Markus Kuhn, Irina Sheidgen y Nicola Valeska Weber. Filmwissenschaftliche Genreanalyse. Eine Einführung. Pp. 245-265. Berlin/Boston.

Spring, J. (2006). Pedagogies of Globalization. The Rise of the Educational Security State. Mahwah, New Jersey: Lawrence Erlbaum Associates.

Spring, J. (2009). Globalization of Education. New York y London: Routledge.

Suvin, D. (1972). On the Poetics of Science Fiction. College English, 34(3), 372-382.

Suvin, D. (1973). La science-fiction et la jungle des genres un voyage extraordinaire. Littérature 10, 98-113.

Suvin, D. (1979). Metamorphoses of Science Fiction. On the Poetics and History of a Literary Genre. New Haven and Londres: Yale University Press.

Suvin, D. (2000). Afterword. In Patrick Parrinder (ed.). Learning from Other Worlds. Estrangement, Cognition and the Politics of Science Fiction and Utopia. Pp. 233-271. Liverpool: Liverpool University Press.

Zajda, J. (2010). Globalisation, Ideology and Education Policy Reforms. In Joseph Zajda (ed.). Globalisation, Ideology and Education Policy Reforms. Pp. xii-xxii. Dordrecht, Heidelberg, London, New York: Springer.

Zgorzelski, A. (1979). Is Science Fiction a Genre of Fantastic Literature? Science Fiction Studies, 6(3), 296-303.

Žižek, S. (2014a). Event. A Philosophical Journey Through a Concept. Brooklyn and Londres: Melville House.

Žižek, S. (2014b). Absolute Recoil. Towards a New Foundation of Dialectical Materialism. Londres and Nueva York: Verso. 